\title{
New Method for Preparation of 1-Amidoalkyl-2-Naphthols via Multicomponent Condensation Reaction Utilizing Tetrachlorosilane under Solvent Free Conditions
}

\author{
Samy B. Said ${ }^{1 *}$, Mohammad M. A. Mashaly ${ }^{1}$, Ahmed M. Sheta ${ }^{1}$, Saad S. Elmorsy² \\ ${ }^{1}$ Chemistry Department, Faculty of Science, Damietta University, New Damietta, Egypt \\ ${ }^{2}$ Chemistry Department, Faculty of Science, Mansoura University, Mansoura, Egypt \\ Email: ${ }^{*}$ sbsaid@yahoo.com
}

Received 26 July 2015; accepted 11 September 2015; published 14 September 2015

Copyright (C) 2015 by authors and Scientific Research Publishing Inc.

This work is licensed under the Creative Commons Attribution International License (CC BY).

http://creativecommons.org/licenses/by/4.0/

(c) (i) Dpen Access

\section{Abstract}

An efficient and direct procedure for the synthesis of amidoalkylnaphthol derivatives employing a multi-component and one-pot condensation reaction of 2-naphthol, aromatic aldehyde and acetonitrile in the presence of tetrachlorosilane (TCS). A binary reagent from (TCS) $/ \mathrm{ZnCl}_{2}$ was used upon applying benzonitrile.

\section{Keywords}

\section{1-Amidoalkyl-2-Naphthol, Tetrachlorosilane (TCS), Multicomponent Reaction}

\section{Introduction}

A recent increased attention witnessed to the use of tetrachlorosilane (TCS), a cheap industrial intermediate, in different areas of the organic chemistry has now reached significant levels, not only for the possibility to perform environmentally benign synthesis, but for the good yield. In continuation of our investigations on the development and applications of new in situ reagents derived from tetrachlorosilane in organic synthesis [1]-[9], we have developed an efficient, general, and convenient protocol for the multicomponent synthesis of 1-amidoal-kyl-2-naphthols.

\footnotetext{
*Corresponding author.
}

How to cite this paper: Said, S.B., Mashaly, M.M.A., Sheta, A.M. and Elmorsy, S.S. (2015) New Method for Preparation of 1-Amidoalkyl-2-Naphthols via Multicomponent Condensation Reaction Utilizing Tetrachlorosilane under Solvent Free Conditions. International Journal of Organic Chemistry, 5, 191-199. http://dx.doi.org/10.4236/ijoc.2015.53019 
Multicomponent coupling reactions (MCRs) represent powerful time-, energy-, and material-saving synthetic protocols in modern chemistry in which molecular complexity could be generated in a single synthetic operation [10] [11].

The preparation of 1-amidoalkyl-2-naphthols can be carried out by multi-component condensation of aryl aldehydes, $\beta$-naphthol and amide derivatives in the presence of Lewis or Bronsted acid catalysts such as $\mathrm{Ce}\left(\mathrm{SO}_{4}\right)_{2}$ [12], montmorillonite $\mathrm{K} 10$ [13], iodine [14], cation exchanged resins [15], $\mathrm{NaHSO}_{4} \cdot \mathrm{H}_{2} \mathrm{O}$ [16], $\mathrm{Fe}(\mathrm{HSO})_{3}$ [17], sulfamic acid/ultrasound [18], $\mathrm{HClO}_{4} / \mathrm{SiO}_{2}$ [19], cyanuric chloride [20] and $\mathrm{K}_{5} \mathrm{CoW}_{12} \mathrm{O}_{40} \cdot 3 \mathrm{H}_{2} \mathrm{O}$ [21]. Some of the reported methods suffer from one or more limitations such as high reaction temperature, lower product yield, tedious work up, and use of toxic reagents. They also lack general applicability to produce arrays of 1-amidoalkyl-2-naphthols as they are restricted to only a few amides. Therefore, the development of a more general, cost-effective multicomponent coupling reaction (MCR) protocol for the synthesis of 1-amidoalkyl-2-naphthols remains a challenge. Therefore the introduction of new, efficient, and general methods involving various nitriles for this multicomponent reaction under milder conditions is still required.

\section{Experimental}

Infrared (IR) spectra were recorded on JASCO 410 spectrometer. Absorption maxima were recorded in cm-1. Nuclear Magnetic Resonance (NMR) spectra were run at Varian-Mercury (300 MHz) FTNMR spectrometer. Spectra were taken using DMSO solvent with chemical shifts quoted in parts per million ( $\delta$ ppm) using TMS as internal standard. The Mass Spectra (M.S.) were recorded on GC-MS QP-2010 EX Schmiadzu (Japan) mass spectrometer. Melting points (uncorrected) were determined in an open capillary with a Griffin melting point apparatus. Column Chromatography was carried out by using Merck Kieselgel 60 GF-254 (230 - 400 mesh). Analytical TLC was performed on aluminum sheets (Merck, Kieselgel 60 F254, Thickness 0.2 mm). Tetrachlorosilane (TCS) was used as obtained from commercial sources. The solvents were distilled and dried before use. Acetonitrile was dried by refluxing over phosphorous pentoxide then distilled. Methylene chloride was dried by refluxing over anhydrous calcium chloride then distilled.

\section{Typical Procedure}

In $50 \mathrm{ml}$ round bottom flask equipped with air condenser and magnetic stirring bar, a mixture of aromatic aldehyde (5 mmol), anhydrous naphthol $(5 \mathrm{mmol})$, and tetrachlorosilane $(1.8 \mathrm{ml}, 15 \mathrm{mmol})$ was allowed to stir at room temperature for 10 minutes. To this reaction mixture, $5 \mathrm{mmol}$ of nitrile [acetonitrile or benzonitrile] was added and the stirring process was continued for further time (monitored by TLC). The reaction mixture was quenched using ice cold water. The aqueous solution was extracted with chloroform $(3 \times 30 \mathrm{ml})$ and then the chloroform extract was dried over anhydrous $\mathrm{Na}_{2} \mathrm{SO}_{4}$ and concentrated over boiling water bath. The residual oil was purified using preparative thin layer chromatography using silica gel to give the products in pure form.

(1) N-((2-Hydroxynaphthalen-1-yl)(phenyl)methyl)acetamide:

$\mathrm{mp} 246^{\circ} \mathrm{C}$ (lit. [12] mp $\left.241^{\circ} \mathrm{C}-243^{\circ} \mathrm{C}\right)$; IR $\left(\mathrm{KBr}, \mathrm{cm}^{-1}\right)$ : 3399, 3245, 3062, 1639, 1581, 1517, 1369, 1334, 1101, 806, 740, 692, 617; 1H-NMR(300 MHz, DMSO-d $\left.\mathrm{d}_{6}\right): \delta$ (ppm) 1.97 (s, 3H), 7.1 - 7.35 (m, $\left.9 \mathrm{H}\right), 7.74-7.85$ (m, 3H), 8.38 (d, J = $9 \mathrm{~Hz}, 1 \mathrm{H}), 9.95$ (s, 1H); ${ }^{13} \mathrm{C}$ NMR(75 MHz, DMSO-d $\left.\mathrm{d}_{6}\right): \delta$ (ppm) 23.5, 41.3, 118.8, 120.2, 122.0, 123.9, 124.9, 125.7, 127.6, 128.1, 128.3, 128.5, 128.6, 134.2, 144.0, 152.6, 169.6; MS: m/z 231(100\%), 232(75.7\%), 233(13.16\%), 291(20.72\%) $\mathrm{M}^{+}$.

(2) N-((4-chlorophenyl)(2-hydroxynaphthalen-1-yl)methyl)acetamide

$\mathrm{mp} 230^{\circ} \mathrm{C}$ (lit. [12] mp $224^{\circ} \mathrm{C}-227^{\circ} \mathrm{C}$ ); IR (KBr, $\mathrm{cm}^{-1}$ ): 3394, 2960, 2705, 2609, 1631, 1581, 1521, 1436, 1371, 1328, 1272, 1240, 1170, 1091, 815, 748, 586, 499.

(3) N-((2-hydroxynaphthalen-1-yl)(p-tolyl)methyl)acetamide:

mp $224^{\circ} \mathrm{C}$ (lit. [17] mp $222^{\circ} \mathrm{C}-223^{\circ} \mathrm{C}$ ); IR ( $\left.\mathrm{KBr}, \mathrm{cm}^{-1}\right)$ : 3394, 2969, 2707, 2616, 1625, 1515, 1436, 1332, 1272, 1174, 1064, 811; ${ }^{1} \mathrm{H}-\mathrm{NMR}\left(300 \mathrm{MHz}, \mathrm{DMSO}-\mathrm{d}_{6}\right): \delta(\mathrm{ppm}) 2.02$ (s, 3H), 2.24 (s, 3H), 7.05 - 7.40(m, 8H),

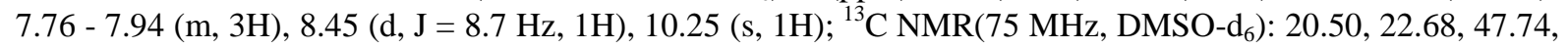
118.53, 119.04, 122.33, 123.31, 126.03, 126.23, 128.52, 129.11, 132.35, 135.04, 139.56, 153.13, 169.18; MS: $\mathrm{m} / \mathrm{z}$ 245(100\%), 246(75.7\%), 247(13.1\%), 305(21\%) $\mathrm{M}^{+}$.

(4)N-((4-(dimethylamino)phenyl)(2-hydroxynaphthalen-1-yl)methyl)acetamide:

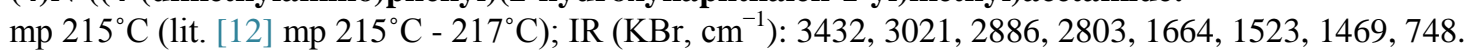

(5) N-((4-formylphenyl)(2-hydroxynaphthalen-1-yl)methyl)acetamide: 


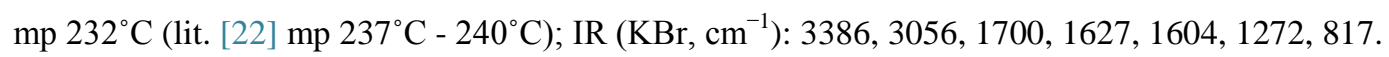

(6) N-((2-bromophenyl)(2-hydroxynaphthalen-1-yl)methyl)acetamide:

$\mathrm{mp} 210^{\circ} \mathrm{C}$ (lit. [23] $\left.\mathrm{mp} \mathrm{204}^{\circ} \mathrm{C}\right)$; IR $\left(\mathrm{KBr}, \mathrm{cm}^{-1}\right)$ : 3421, 3122, 1656, 1517, 1434, 1058, 817, 752.

(7) N-((3-bromophenyl)(2-hydroxynaphthalen-1-yl)methyl)acetamide:

$\mathrm{mp} 230^{\circ} \mathrm{C}$ (lit. [24] mp $\left.229^{\circ} \mathrm{C}-230^{\circ} \mathrm{C}\right)$; IR $\left(\mathrm{KBr}, \mathrm{cm}^{-1}\right)$ : 3407, 3164, 1643, 1517, 1436, 1066, 811, 748.

(8) N-((2-nitrophenyl)(2-hydroxynaphthalen-1-yl)methyl)acetamide:

$\mathrm{mp} 215^{\circ} \mathrm{C}$ (lit. [25] $\left.\mathrm{mp} 218^{\circ} \mathrm{C}-219^{\circ} \mathrm{C}\right)$; IR $\left(\mathrm{KBr}, \mathrm{cm}^{-1}\right): 3410,3265,1643,1590,1520,1415,1345,1305$, 1225, 1105, 1010, 950, 852, 745.

(9) N-((3-nitrophenyl)(2-hydroxynaphthalen-1-yl)methyl)acetamide:

mp $180^{\circ} \mathrm{C}$ (lit. [25] mp $\left.256^{\circ} \mathrm{C}-258^{\circ} \mathrm{C}\right)$; IR $\left(\mathrm{KBr}, \mathrm{cm}^{-1}\right)$ : 3241, 1625, 1596, 1525, 1436, 1346, 1286, 1211 , 1091, 1014, 948, 856, 732; ${ }^{1} \mathrm{H}-\mathrm{NMR}\left(300 \mathrm{MHz}, \mathrm{DMSO}-\mathrm{d}_{6}\right): \delta(\mathrm{ppm}) 2.06(\mathrm{~s}, 3 \mathrm{H}), 7.15-7.49(\mathrm{~m}, 6 \mathrm{H}), 7.78$ $8.04(\mathrm{~m}, 5 \mathrm{H}), 8.54(\mathrm{~d}, \mathrm{~J}=8.1 \mathrm{~Hz}, 1 \mathrm{H}), 10.12(\mathrm{~s}, 1 \mathrm{H}) ;{ }^{13} \mathrm{C}$ NMR(75 MHz, DMSO-d $\left.\mathrm{d}_{6}\right): 25.55,66.13,108.61$, 118.16, 120.28, 122.32, 123.94, 125.57, 127.46, 128.4, 129.20, 129.46, 130.84, 132.08, 134.82, 147.69, 148.04, 152.49, 191.67; MS: m/z 276(100\%), 277(75.7\%), 278(13.16\%), 336(13\%) $\mathrm{M}^{+}$.

(10) N-((4-methoxyphenyl)(2-hydroxynaphthalen-1-yl)methyl)acetamide:

$\mathrm{mp} 178^{\circ} \mathrm{C}$ (lit. [17] $\left.\mathrm{mp} 183^{\circ} \mathrm{C}-186^{\circ} \mathrm{C}\right)$; IR $\left(\mathrm{KBr}, \mathrm{cm}^{-1}\right)$ : 3399, 3245, 1639, 1511, 1438, 1365, 1303, 1247, 1172, 1029, 815, 748.

(11) N-((2-hydroxynaphthalen-1-yl)(phenyl)methyl)benzamide:

mp $230^{\circ} \mathrm{C}$ (lit. [26] mp $235^{\circ} \mathrm{C}-237^{\circ} \mathrm{C}$ ); IR $\left(\mathrm{KBr}, \mathrm{cm}^{-1}\right)$ : 3413, 3222, 1629, 1531, 1488, 1346, 752; ${ }^{1} \mathrm{H}-\mathrm{NMR}$ $\left(300 \mathrm{MHz}, \mathrm{DMSO}-\mathrm{d}_{6}\right): \delta(\mathrm{ppm}) 7.23-8(\mathrm{~m}, 17 \mathrm{H}), 9.01(1 \mathrm{H}, \mathrm{d}, \mathrm{J}=9 \mathrm{~Hz}), 10.3(1 \mathrm{H}, \mathrm{s}) ;{ }^{13} \mathrm{C}$ NMR(75 MHz, DMSO-d $\mathrm{d}_{6}$ ): 167.30, 155.13, 142.59, 135.39, 132.59, 131.44, 130.27, 128.53, 128.42, 128.08, 127.98, 127.36, 126.99, 126.88, 126.56, 122.55, 117.26, 62.66; MS: m/z 233 (6.5\%), 232 (42.25\%), 231 (100\%), 353 (4.74\%) M+.

(12) N-((4-chlorophenyl)(2-hydroxynaphthalen-1-yl)methyl)benzamide:

$\mathrm{mp} 191^{\circ} \mathrm{C}$ (lit. [27] mp $\left.185^{\circ} \mathrm{C}-186^{\circ} \mathrm{C}\right)$; IR $\left(\mathrm{KBr}, \mathrm{cm}^{-1}\right)$ : 3424, 3116, 1633, 1569, 1535, 1484, 1434, 1344, $1270,819,707$.

(13) N-((2-hydroxynaphthalen-1-yl)(p-tolyl)methyl)benzamide:

mp $213^{\circ} \mathrm{C}$ (lit. [27] mp $\left.216^{\circ} \mathrm{C}-218^{\circ} \mathrm{C}\right)$; IR $\left(\mathrm{KBr}, \mathrm{cm}^{-1}\right)$ : 3413, 1631, 1533, 1346, 1272, 1078, 817.

(14) N-((2-hydroxynaphthalen-1-yl)(4-methoxyphenyl)methyl)benzamide:

mp $196^{\circ} \mathrm{C}$ (lit. [28] mp $\left.197^{\circ} \mathrm{C}-199^{\circ} \mathrm{C}\right)$; IR $\left(\mathrm{KBr}, \mathrm{cm}^{-1}\right)$ : 3423, 1625, 1571, 1511, 1436, 1348, 1263, 1174 , 1029, 933, 821; ${ }^{1} \mathrm{H}-\mathrm{NMR}\left(300 \mathrm{MHz}\right.$, DMSO-d $\left.\mathrm{d}_{6}\right): \delta(\mathrm{ppm}) 10.38(1 \mathrm{H}, \mathrm{s}), 9.05(1 \mathrm{H}, \mathrm{d}, \mathrm{J}=8.7 \mathrm{~Hz}), 8.11(1 \mathrm{H}, \mathrm{d}, \mathrm{J}$ = 8.4 Hz),7.79 - $7.90(3 \mathrm{H}, \mathrm{m}), 7.45-7.55(2 \mathrm{H}, \mathrm{m}), 7.25-7.32(3 \mathrm{H}, \mathrm{m}), 6.84(2 \mathrm{H}, \mathrm{d}, \mathrm{J}=8.7 \mathrm{~Hz}), 3.68(3 \mathrm{H}, \mathrm{s}) ;{ }^{13} \mathrm{C}$ NMR(75 MHz, DMSO-d $\left.\mathrm{d}_{6}\right)$ : 48.98, 54.98, 113.61, 118.48, 118.76, 122.65, 126.69, 127.02, 127.73, 128.38, 128.47, 12858, 129.21, 131.33, 132.25, 133.92, 134.43, 153.07, 158.05, 165.54; MS: m/z 263 (16.5\%), 262 (40.5\%), 261 (100\%), $383(5.7 \%) \mathrm{M}^{+}$.

(15) N-((4-(dimethylamino)phenyl)(2-hydroxynaphthalen-1yl)methyl)benzamide:

mp $220^{\circ} \mathrm{C}$ (lit. [25] mp $220^{\circ} \mathrm{C}-221^{\circ} \mathrm{C}$ ); IR $\left(\mathrm{KBr}, \mathrm{cm}^{-1}\right)$ : 3405, 3273, 1631, 1573, 1521, 1434, 1340, 1180, 1029, 939, 811.

(16) N-((2-hydroxynaphthalen-1-yl)(2-nitrophenyl)methyl)benzamide:

$\mathrm{mp} 261^{\circ} \mathrm{C}$ (lit. [25] mp $266^{\circ} \mathrm{C}-267^{\circ} \mathrm{C}$ ); IR $\left(\mathrm{KBr}, \mathrm{cm}^{-1}\right)$ : 3440, 3145, 1649, 1510, 1490, 1441, 1347, 1249, 805, 712.

(17) N-((2-hydroxynaphthalen-1-yl)(3-nitrophenyl)methyl)benzamide:

$\mathrm{mp} 220^{\circ} \mathrm{C}$ (lit. [21] mp $216^{\circ} \mathrm{C}-218^{\circ} \mathrm{C}$ ); IR $\left(\mathrm{KBr}, \mathrm{cm}^{-1}\right)$ : 3413, 3180, 1644, 1522, 1468, 1428, 1356, 1272, 800, 712.

(18) N-((2-hydroxynaphthalen-1-yl)(4-nitrophenyl)methyl)benzamide:

$\mathrm{mp} 226^{\circ} \mathrm{C}$ (lit. [21] mp $\left.228^{\circ} \mathrm{C}-230^{\circ} \mathrm{C}\right)$; IR $\left(\mathrm{KBr}, \mathrm{cm}^{-1}\right)$ : 3444, 3155, 1649, 1510, 1493, 1447, 1347, 1244, 803, 713; ${ }^{1} \mathrm{H}-\mathrm{NMR}\left(300 \mathrm{MHz}\right.$, DMSO-d $\mathrm{d}_{6}$ ): $\delta$ (ppm) 10.24 (s, $\left.1 \mathrm{H}, \mathrm{OH}\right), 7.98$ (d, J =7.8 Hz, 1H), 9.00 (d, J = 8.0 Hz, 1H), 7.10 - 7.25 (m, 4H, ArH), 7.46 - 7.66 (m, 7H, ArH), 7.76 - 7.98 (m, 4H, ArH); ${ }^{13} \mathrm{C}$ NMR(75 MHz, DMSO$\left.\mathrm{d}_{6}\right)$ : 48.20, 116.29, 118.78, 119.94, 122.49, 125.42, 126.91, 128.54, 128.84, 129.55, 130.27, 131.48, 131.96, 132.69, 134.32, 141.78, 153.72, 165.44; MS: m/z 278(4.5\%), 277(43.25\%), 276(100\%), 384(4.\%) $\mathrm{M}^{+}$.

\section{Results and Discussion}

With the aim to develop more efficient synthetic processes and convenient protocol; for the one-pot synthesis of 
1-amidoalkyl-2-naphthols, biologically active drug like molecules [29]-[31]. We herein describe a practical, inexpensive protocol for the preparation of 1-amidoalkyl-2-naphthols via multi component condensation reaction between various aromatic aldehydes, $\beta$-naphthols and nitriles including alkyl and aryl nitrile using readily available tetrachlorosilane (TCS) reagent at room temperature, and solvent-free conditions. To test the general scope and versatility of this procedure in the synthesis of a variety of substituted amidoalkyl naphthols, we examined a number of different substituted aromatic aldehydes, 2-naphthol and acetonitrile. To optimize the reaction condition, the reaction of benzaldehyde, $\beta$-naphthol and acetonitrile was selected as a model to investigate the effects of different amounts of reagent on the yield. The best result was obtained by carrying out the reaction with one molar amounts of aldehyde and $\beta$-naphthol, and two molar amounts of acetonitrile as shown in Table 1. We also examined the reaction in various solvents. Chlorinated solvents such as methylene chloride or 1,2-dichloroethane were found to be ineffective solvents yielding the reaction product in very low conversion. The donor solvents such as tetrahydrofuran (THF) and diethyl ether (DEE) were completely inhibited the reaction.

The reaction between benzaldehyde, acetonitrile and 2-naphthol was carried out without TCS and we found that no reaction takes place. To determine the optimum quantity of TCS, the reaction was carried out at room temperature. The use of two equimolar amounts of TCS, resulted in the highest yield. The molar ratio of aldehyde, $\beta$-naphthol, acetonitrile and TCS was kept at 1:1:2:2, respectively (Scheme 1).

Thus we prepared a range of 1-amidoalkyl-2-naphthols under the optimized reaction conditions: stirring the $\beta$-naphthol (1 mmol), aryl aldehydes $(1 \mathrm{mmol})$ and acetonitrile $(2 \mathrm{mmol})$ in the presence of tetrachlorosilane (2 $\mathrm{mmol}$ ) at room temperature. A series of 1-amidoalkyl-2-naphthols were prepared in high to excellent yields (Table 2).

In the case of aromatic aldehydes the three-component reaction proceeded smoothly to give the corresponding 1-amidoalkyl-2-naphthols in high yields. Due to the availability of a vast number of aromatic aldehydes, this three component reaction can be very useful to synthesis the desired products.

As Table 2 shows that, the reaction proved to be general and tolerated a variety of aromatic aldehydes with substituent carrying either electron-donating (Table 2, entries 2, 3, 4, 6, 7, and 10) or electron-withdrawing groups (Table 2, entries 5, 8, and 9). Although as can be seen from the results of table, this reaction is affected by electronic and steric factors.

The suggested mechanism for this reaction is depicted in Scheme 2. This mechanism involves 1,2-addition of tetrachlorosilane (TCS) to aldehyde to produce silyl ether intermediate [A]. On the other hand, 2-naphthol reacted with TCS and produce silyl enol ether [B] and $\mathrm{HCl}$. As reported in literature [32] [33] the reaction of 2-naphthol with aromatic aldehydes in the presence of Lewis acid is known to give ortho-quinone methides (o-QMs). The same $o-\mathrm{QMs}$, generated in-situ, intermediate [E] have been reacted with nitrilium salt [34] [35] [C] to form 1-amidoalkyl-2-naphthol after hydrolysis (Scheme 1). The reaction gave the desired products in the Ritter type reaction [36] [37] at room temperature.

To our knowledge, there is no general protocol employing aromatic nitrile in such addition so far. Therefore, we examined the reaction of benzonitrile with aldehyde, $\beta$-naphthol and TCS as representative example to aryl nitrile. It is noteworthy that no reaction was observed under the above conditions to give the corresponding

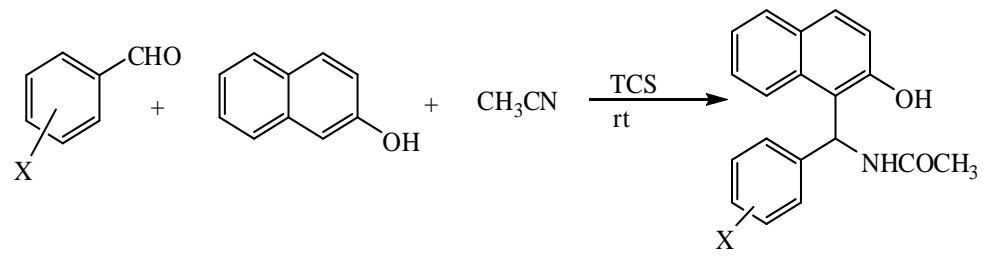

Scheme 1. Reaction of different aldehydes, acetonitrile and 2-naphthol.

Table 1. Effect of different molar ratio on the yield of product.

\begin{tabular}{cccc}
\hline Molar ratio between benzaldehyde, 2-naphthol and acetonitrile & Reaction time (hr) & 15 \\
\hline $1: 1: 1$ & $1: 1: 2$ & 15 & 73 \\
$2: 1: 1$ & 63 & 15 \\
\hline
\end{tabular}


Table 2. Reaction of aldehydes with $\beta$-naphthol and acetonitrile in the presence of tetrachlorosilane.

\begin{tabular}{|c|c|c|c|c|c|}
\hline Entry & Reactant & Time (hr) & Product name & Yield (\%) & Product structure \\
\hline 1 & $\mathrm{C}_{6} \mathrm{H}_{5} \mathrm{CHO}$ & 15 & $\begin{array}{l}N \text {-((2-hydroxynaphthalen-1-yl) } \\
\text { (phenyl)methyl) acetamide }\end{array}$ & 83 & \\
\hline 2 & $p-\mathrm{ClC}_{6} \mathrm{H}_{4} \mathrm{CHO}$ & 14 & $\begin{array}{c}N \text {-((4-chlorophenyl) (2-hydroxy } \\
\text { naphthalen-1-yl)methyl) acetamide }\end{array}$ & 78 & \\
\hline 3 & $p-\mathrm{CH}_{3} \mathrm{C}_{6} \mathrm{H}_{4} \mathrm{CHO}$ & 17 & $\begin{array}{l}N \text {-((2-hydroxynaphthalen-1-yl) } \\
\text { (p-tolyl)methyl) acetamide }\end{array}$ & 79 & \\
\hline 4 & $p-(\mathrm{Me}){ }_{2} \mathrm{NC}_{6} \mathrm{H}_{4} \mathrm{CHO}$ & 18 & $\begin{array}{c}N \text {-((4-(dimethylamino)phenyl) } \\
\text { (2-hydroxynaphthalen-1-yl) } \\
\text { methyl)acetamide }\end{array}$ & 65 & \\
\hline 5 & $p-\mathrm{OHCC}_{6} \mathrm{H}_{4} \mathrm{CHO}$ & 13 & $\begin{array}{c}N \text {-((4-formylphenyl) (2-hydroxy } \\
\text { naphthalen-1-yl)methyl) acetamide }\end{array}$ & 70 & \\
\hline 6 & $o-\mathrm{BrC}_{6} \mathrm{H}_{4} \mathrm{CHO}$ & 13 & $\begin{array}{c}N \text {-((2-bromophenyl) (2-hydroxy } \\
\text { naphthalen-1-yl)methyl) acetamide }\end{array}$ & 85 & \\
\hline 7 & $m-\mathrm{BrC}_{6} \mathrm{H}_{4} \mathrm{CHO}$ & 14 & $\begin{array}{c}N \text {-((3-bromophenyl) (2-hydroxy } \\
\text { naphthalen-1-yl)methyl) acetamide }\end{array}$ & 80 & \\
\hline 8 & $o-\mathrm{O}_{2} \mathrm{NC}_{6} \mathrm{H}_{4} \mathrm{CHO}$ & 18 & $\begin{array}{l}N \text {-((2-nitrophenyl) (2-hydroxy } \\
\text { naphthalen-1-yl)methyl) acetamide }\end{array}$ & 67 & \\
\hline 9 & $m-\mathrm{O}_{2} \mathrm{NC}_{6} \mathrm{H}_{4} \mathrm{CHO}$ & 18 & $\begin{array}{c}N \text {-((3-nitrophenyl) (2-hydroxy } \\
\text { naphthalen-1-yl)methyl) acetamide }\end{array}$ & 70 & \\
\hline 10 & $p-\mathrm{CH}_{3} \mathrm{OC}_{6} \mathrm{H}_{4} \mathrm{CHO}$ & 14 & $\begin{array}{l}N \text {-((4-methoxyphenyl) (2-hydroxy } \\
\text { naphthalen-1-yl) methyl) acetamide }\end{array}$ & 73 & \\
\hline
\end{tabular}


1-amidoalkyl-2-naphthols typically. The use of two equivalents of benzonitrile and tetrachlorosilane and one equivalent of zinc chloride as a binary reagent in the reaction resulted in the highest yield of $N$-((2-hydroxynaphthalen-1-yl) (phenyl)methyl)benzamide, which might be attributed to steric factors as well as to the low of nucleophilicity of benzonitrile (Scheme 3 ).

As shown in Table 3, reaction of aldehydes with $\beta$-naphthol and benzonitrile in the presence of tetrachlorosilane and zinc chloride as a binary reagent under solvent- free conditions at room temperature produced highest yields from 1-benzamidomethyl-2-naphthol derivatives.

Attempts to bring aliphatic aldehydes such as acetaldehyde into the reaction with 2-naphthol and acetonitrile under mild conditions were mostly unsuccessful. Therefore no other aliphatic Aldehydes were examined. To regard the purity of the compounds prepared, melting point and infrared spectra were matched with previously reported literature data. NMR and MS analysis to some compounds revealed the correct structure of the products obtained.

\section{Conclusion}

An efficient one-pot method has been developed for the synthesis of 1-amidoalkyl-2-naphthols from condensation of aldehyde, $\beta$-naphthol, acetonitrile and TCS as condensing reagent. The present methodology gives several

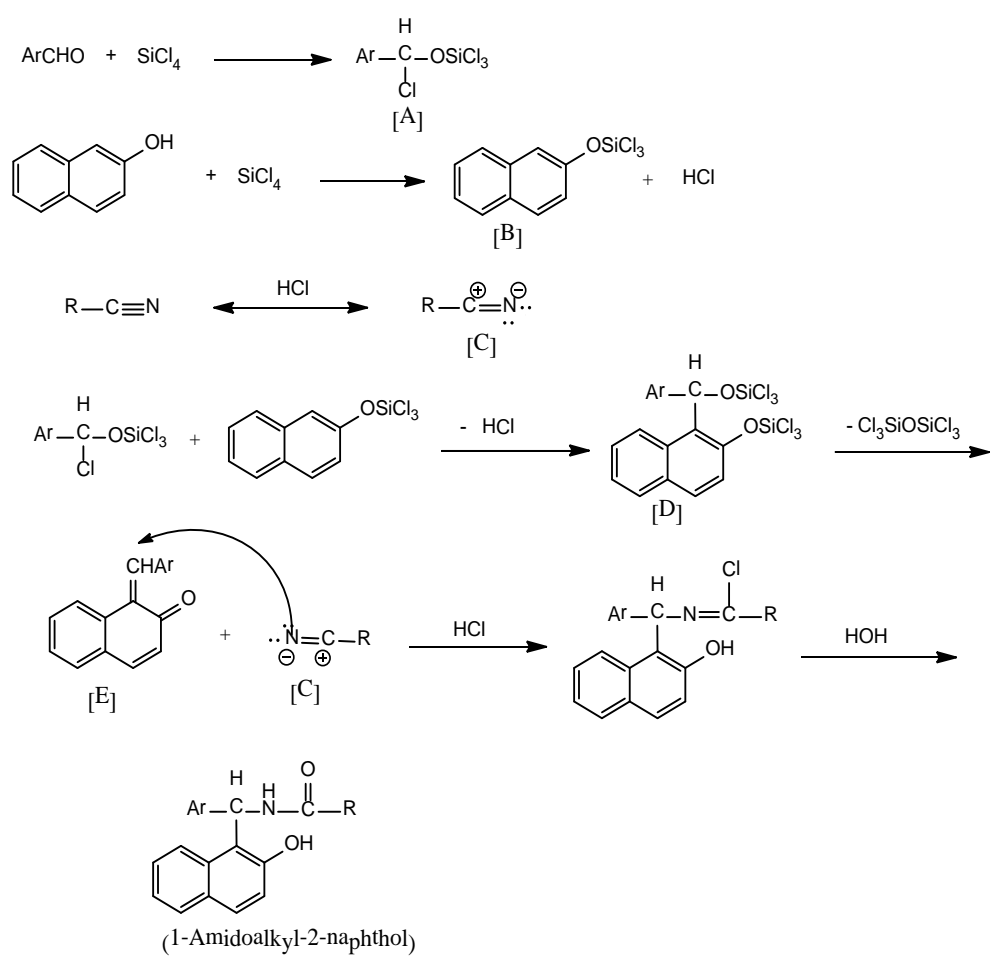

Scheme 2. Suggested mechanism for the formation of 1-amidoal-kyl-2-naphthol.

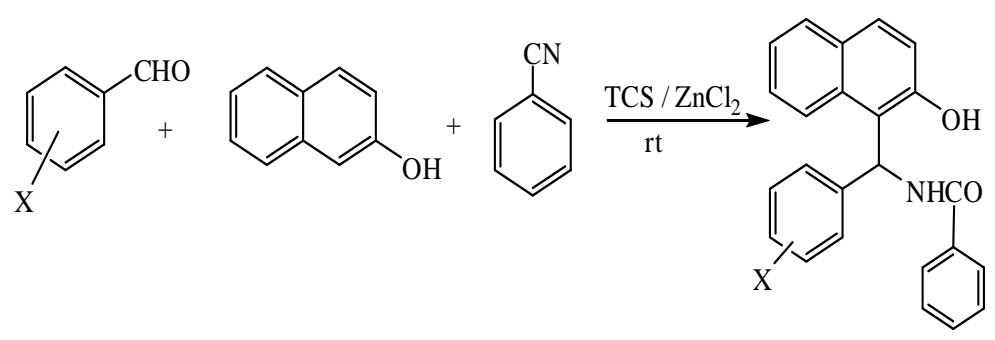

Scheme 3. Reaction of different aldehydes, benzonitrile and 2-naphthol. 
Table 3. Synthesis 1-benzamidomethyl-2-naphthol derivatives in the presence of $\mathrm{TCS} / \mathrm{ZnCl}_{2}$ at r.t. under solvent- free conditions.

\begin{tabular}{|c|c|c|c|c|c|}
\hline entry & Reactant & Time (hr) & Product name & Yield (\%) & Product structure \\
\hline 11 & $\mathrm{C}_{6} \mathrm{H}_{5} \mathrm{CHO}$ & 10 & $\begin{array}{l}N \text {-((2-hydroxynaphthalen-1-yl) } \\
\text { (phenyl)methyl) benzamide }\end{array}$ & 88 & \\
\hline 12 & $p-\mathrm{ClC}_{6} \mathrm{H}_{4} \mathrm{CHO}$ & 8 & $\begin{array}{c}N \text {-((4-chlorophenyl) (2-hydroxy } \\
\text { naphthalen-1-yl)methyl) benzamide }\end{array}$ & 80 & \\
\hline 13 & $p-\mathrm{CH}_{3} \mathrm{C}_{6} \mathrm{H}_{4} \mathrm{CHO}$ & 8 & $\begin{array}{l}N \text {-((2-hydroxynaphthalen-1-yl) } \\
\text { (p-tolyl)methyl) benzamide }\end{array}$ & 76 & \\
\hline 14 & $p-\mathrm{CH}_{3} \mathrm{O} \mathrm{C}{ }_{6} \mathrm{H}_{4} \mathrm{CHO}$ & 8 & $\begin{array}{l}N \text {-((4-methoxyphenyl)(2-hydrox } \\
\text { ynaphthalen-1-yl) methyl) } \\
\text { benzamide }\end{array}$ & 77 & \\
\hline 15 & $p$-(Me $)_{2} \mathrm{NC}_{6} \mathrm{H}_{4} \mathrm{CHO}$ & 11 & $\begin{array}{l}N \text {-((4-(dimethylamino)phenyl) } \\
\text { (2-hydroxynaphthalen-1-yl) } \\
\text { methyl)benzamide }\end{array}$ & 73 & \\
\hline 16 & $o-\mathrm{O}_{2} \mathrm{NC}_{6} \mathrm{H}_{4} \mathrm{CHO}$ & 9 & $\begin{array}{c}N \text {-((2-nitrophenyl) (2-hydroxy } \\
\text { naphthalen-1-yl)methyl) benzamide }\end{array}$ & 82 & \\
\hline 17 & $m-\mathrm{O}_{2} \mathrm{NC}_{6} \mathrm{H}_{4} \mathrm{CHO}$ & 8 & $\begin{array}{c}N \text {-((3-nitrophenyl) (2-hydroxy } \\
\text { naphthalen-1-yl)methyl) benzamide }\end{array}$ & 85 & \\
\hline 18 & $p-\mathrm{O}_{2} \mathrm{NC}_{6} \mathrm{H}_{4} \mathrm{CHO}$ & 9 & $\begin{array}{c}N \text {-((4-nitrophenyl)(2-hydroxy } \\
\text { naphthalen-1-yl)methyl) benzamide }\end{array}$ & 79 & \\
\hline
\end{tabular}

advantages such as simple procedure, easy workup, high yields, and solvent free reaction conditions. The salient feature of this methodology includes an easy purification, generality and in addition no cumbersome apparatus were needed.

\section{References}

[1] Azumaya, I., Kagechika, H., Yamaguchi, K. and Shudo, K. (1996) Facile Formation of Aromatic Cyclic N-Methylamides Based on cis Conformational Preference. Tetrahedron Letters, 37, 5003-5006. http://dx.doi.org/10.1016/0040-4039(96)00995-1 
[2] Elmorsy, S.S., Pelter, A. and Smith, K. (1991) The Direct Production of Tri- and Hexa-Substituted Benzenes from Ketones Under Mild Conditions. Tetrahedron Letters, 32, 4175-4176. http://dx.doi.org/10.1016/S0040-4039(00)79896-0

[3] Elmorsy, S.S., Pelter, A., Smith, K., Hursthouse, M.B. and Ando, D. (1992) Investigations of the TetrachlorosilaneEthanol Induced Self Condensations of Ketones. Tetrahedron Letters, 33, 821-824. http://dx.doi.org/10.1016/S0040-4039(00)77724-0

[4] Elmorsy, S.S., Khalil, A.M., Girges, M.M. and Salama, T.A. (1997) A New Approach to the Stereoselective Synthesis of $\beta$-Methylchalcones. Journal of Chemical Research, Synopses, No. 7, 232-233. http://dx.doi.org/10.1039/a607611d

[5] Elmorsy, S.S., El-Ahl, A.S., Soliman, H.A. and Amer, F.A. (1995) Synthesis of Triazidochlorosilane (TACS). A Novel Silicon Mediated One Pot Conversion of Aldehydes to Nitriles. Tetrahedron Letters, 36, 2639-2640. http://dx.doi.org/10.1016/0040-4039(95)00302-S

[6] Salama, T.A., El-Ahl, A.S., Khalil, A.M., Girges, M.M., Lackner, B., Steindi, C. and Elmorsy, S.S. (2003) A Convenient Regiospecific Synthesis of New Conjugated Tetrazole Derivatives via the Reaction of Dienones with the Tetrachlorosilane-Sodium Azide Reagent and their NMR Structural Assignment. Monatshefte für Chemie, 134, 12411252. http://dx.doi.org/10.1007/s00706-003-0045-X

[7] Salama, T.A., Elmorsy, S.S., Khalil, A. M., Girges, M.M. and El-Ahl, A.S. (2007) Novel Uncatalyzed Hydrocyanation of Ketones utlizing Tetrachlorosilane-Potassium Cyanide Reagent. Synthetic Communications, 37, 1313-1319. http://dx.doi.org/10.1080/00397910701226897

[8] Salama, T.A., Elmorsy, S.S., Khalil, A.M. and Ismail, M.A. (2007) $\mathrm{A} \mathrm{SiCl}_{4}-\mathrm{ZnCl}_{2}$ Induced General, Mild and Efficient One-Pot, Three-Component Synthesis of $\beta$-Amido Ketone Libraries. Tetrahedron Letters, 48, 6199-6203. http://dx.doi.org/10.1016/j.tetlet.2007.06.128

[9] Salama, A.T., Ismail, A.M., Khalil, M.A. and Elmorsy, S.S. (2012) Silicon-Assisted O-Heterocyclic Synthesis: Mild and Efficient One-Pot Syntheses of (E)-3-Benzylideneflavanones, Coumarin-3-Carbonitriles/Carboxamides, and Benzannulated Spiropyran Derivatives. Archive for Organic Chemistry, 2012, 242-253.

[10] Thomson, L.A. and Elman, J.A. (1996) Synthesis and Applications of Small Molecule Libraries. Chemical Reviews, 96, 555-600. http://dx.doi.org/10.1021/cr9402081

[11] Hulme, C. and Gore, V. (2003) Multi-Component Reactions: Emerging Chemistry in Drug Discovery "From Xylocain to Crixivan”. Current Medicinal Chemistry, 10, 51-80. http://dx.doi.org/10.2174/0929867033368600

[12] Selvam, N.P. and Perumal, P.T. (2006) A New Synthesis of Acetamido Phenols Promoted by Ce(SO 4$)_{2}$. Tetrahedron Letters, 47, 7481-7483. http://dx.doi.org/10.1016/j.tetlet.2006.08.038

[13] Kantevari, S., Vuppalapati, S.V.N. and Nagarapu, L. (2007) Montmorillonite K10 Catalyzed Efficient Synthesis of Amidoalkyl Naphthols under Solvent Free Conditions. Catalysis Communications, 8, 1857-1862. http://dx.doi.org/10.1016/j.catcom.2007.02.022

[14] Das, B., Laxminarayana, K., Ravikanth, B. and Rao, B.R. (2007) Iodine Catalyzed Preparation of Amidoalkyl Naphthols in Solution and under Solvent-Free Conditions. Journal of Molecular Catalysis A: Chemical, 261, 180-183. http://dx.doi.org/10.1016/j.molcata.2006.07.077

[15] Patil, S.B., Singh, P.R., Surpur, M.P. and Samant, S.D. (2007) Cation-Exchanged Resins: Efficient Heterogeneous Catalysts for Facile Synthesis of 1-Amidoalkyl-2-naphthols from One-Pot, Three-Component Condensations of Amides/Ureas, Aldehydes, and 2-Naphthol. Synthetic Communications, 37, 1659-1664. http://dx.doi.org/10.1080/00397910701263858

[16] Shaterian, H.R. and Yarahmadi, H. (2008) Sodium Hydrogen Sulfate as Effective and Reusable Heterogeneous Catalyst for the One-Pot Preparation of Amidoalkyl Naphthols. ARKIVOC, 2008, 105-114. http://www.arkat-usa.org/get-file/23225/

[17] Shaterian, H.R., Yarahmadi, H. and Ghashang, M. (2008) An Efficient, Simple and Expedition Synthesis of 1-Amidoalkyl-2-naphthols as "Drug Like” Molecules for Biological Screening. Bioorganic \& Medicinal Chemistry Letters, 18, 788-792. http://dx.doi.org/10.1016/j.bmcl.2007.11.035

[18] Patil, S.B., Singh, P.R., Surpur, M.P. and Samant, S.D. (2007) Ultrasound-Promoted Synthesis of 1-Amidoalkyl-2naphthols via a Three-Component Condensation of 2-Naphthol, Ureas/Amides, and Aldehydes, Catalyzed by Sulfamic Acid under Ambient Conditions. Ultrasonics Sonochemistry, 14, 515-518. http://dx.doi.org/10.1016/j.ultsonch.2006.09.006

[19] Shaterian, H.R., Yarahmadi, H. and Ghashang, M. (2008) Silica Supported Perchloric Acid $\left(\mathrm{HClO}_{4}-\mathrm{SiO}_{2}\right)$ : An Efficient and Recyclable Heterogeneous Catalyst for the One-Pot Synthesis of Amidoalkyl Naphthols. Tetrahedron, 64, 12631269. http://dx.doi.org/10.1016/j.tet.2007.11.070

[20] Mahdavinia, G.H. and Bigdeli, M.A. (2009) Wet Cyanuric Chloride Promoted Efficient Synthesis of Amidoalkyl Naphthols under Solvent-Free Conditions. Chinese Chemical Letters, 20, 383-386. http://dx.doi.org/10.1016/j.cclet.2008.12.018 
[21] Nagarapu, L., Baseeruddin, M., Apuri, S. and Kantevari, S. (2007) Potassium Dodecatungstocobaltate Trihydrate $\left(\mathrm{K}_{5} \mathrm{CoW}_{12} \mathrm{O}_{40} \cdot 3 \mathrm{H}_{2} \mathrm{O}\right)$ : A Mild and Efficient Reusable Catalyst for the Synthesis of Amidoalkyl Naphthols in Solution and under Solvent-Free Conditions. Catalysis Communications, 8, 1729-1734. http://dx.doi.org/10.1016/j.catcom.2007.02.008

[22] Zare, A., Hasaninejad, A., Rostami, E., Moosavi-Zare, A.R., Roshankar, N., Khedri, F. and Khedri, M. (2010) An Efficient Solvent-Free Protocol for the Synthesis of 1-Amidoalkyl-2-naphthols Using Silica-Supported Molybdatophosphoric Acid. E-Journal of Chemistry, 7, 1162-1169. http://dx.doi.org/10.1155/2010/512392

[23] Zandi, M. and Sardarian, A.R. (2012) Eco-Friendly and Efficient Multi-Component Method for Preparation of 1Amidoalkyl-2-naphthols under Solvent-Free Conditions by Dodecylphosphonic Acid (DPA). Comptes Rendus Chimie, 15, 365-369. http://dx.doi.org/10.1016/j.crci.2011.11.012

[24] Shahrisa, A., Somayehesmati and Nazari, M.G. (2012) Boric Acid as a Mild and Efficient Catalyst for One-Pot Synthesis of 1-Amidoalkyl-2-naphthols under Solvent-Free Conditions. Journal of Chemical Sciences, 124, 927-931. http://dx.doi.org/10.1007/s12039-012-0285-6

[25] Nandi, G.C, Samai, S., Kumar, R. and Singh, M.S (2009) Atom-Efficient and Environment-Friendly Multicomponent Synthesis of Amidoalkyl Naphthols Catalyzed by $\mathrm{P}_{2} \mathrm{O}_{5}$. Tetrahedron Letters, 50, 7220-7222. http://dx.doi.org/10.1016/j.tetlet.2009.10.055

[26] Nagawade, R.R. and Shinde, D.B. (2007) Zirconyl(IV) Chloride-Catalyzed Multicomponent Reaction of $\beta$-Naphthols: An Expeditious Synthesis of Amidoalkyl Naphthols. Acta Chimica Slovenica, 54, 642-646.

[27] Sapanamalik, S. and Singh, R.K. (2012) Microwave Assisted Synthesis of 1-Amidoalkyl-2-naphthols Catalyzed by Anhydrous Zinc Chloride. Asian Journal of Chemistry, 24, 5669-5672.

[28] Jiang, W.Q.L., An, T.J. and Zou, P. (2008) Molybdophosphoric Acid: An Efficient Keggin-Type Heteropoloacid Catalyst for the One-Pot Three-Component Synthesis of 1-Amidoalkyl-2-naphthols. Chinese Journal of Chemistry, 26, 1697-1701. http://dx.doi.org/10.1002/cjoc.200890307

[29] Dingermann, T., Steinhilber, D. and Folkers, G. (2004) Molecular Biology in Medicinal Chemistry. Wiley-VCH, Weinheim.

[30] Shen, A.Y., Tsai, C.T. and Chen, C.L. (1999) Synthesis and Cardiovascular Evaluation of N-Substituted 1-Aminomethyl2-naphthols. European Journal of Medicinal Chemistry, 34, 877-882. http://dx.doi.org/10.1016/S0223-5234(99)00204-4

[31] Shen, A.Y., Chen, C.L. and Lin, C.I. (1992) Electrophysiological Basis for the Bradycardic Effects of 1-(1-Pyrrolidinylmethyl)-2-naphthol in Rodents. Chinese Journal of Physiology, 35, 45-54.

[32] Khodaei, M.M., Khosropour, A.R. and Oghanian, H.M. (2006) A Simple and Efficient Procedure for the Synthesis of Amidoalkyl Naphthols by p-TSA in Solution or under Solvent-Free Conditions. Synlett, 2006, 916-920. http://dx.doi.org/10.1055/s-2006-939034

[33] Haaf, W. (1963) Studies on Ritter Reaction. Chemische Berichte, 96, 3359-3369. http://dx.doi.org/10.1002/cber.19630961237

[34] Ziegler, E., Kleineberg, G. and Meindle, H. (1963) Synthesen von Heterocyclen, 46. Mitt.: Über Reaktionen mit Ketensäurechloriden (Kurze vorläufige Mitteilung). Monatshefte für Chemie, 94, 544-548. http://dx.doi.org/10.1007/BF00903495

[35] Ritter, J.J. and Minieri, P.P. (1948) A New Reaction of Nitriles. I. Amides from Alkenes and Mononitriles. Journal of the American Chemical Society, 70, 4045-4048. http://dx.doi.org/10.1021/ja01192a022

[36] Tillmanns, E.J. and Ritter, J.J. (1957) Notes-Nitriles in Nuclear Heterocyclic Syntheses. I. Dihydro-1,3 Oxazines. The Journal of Organic Chemistry, 22, 839-840. http://dx.doi.org/10.1021/jo01358a612

[37] Smith, P.A.S. and Sullivan, J.M. (1961) The Cyclization of N-Alkenylthionamides to Thiazolines and Dihydrothiazines. The Journal of Organic Chemistry, 26, 1132-1136. http://dx.doi.org/10.1021/jo01063a038 